\title{
Expression of the exocytotic protein syntaxin in mouse oocytes
}

\author{
K. Iwahashi ${ }^{1}$, N. Kuji ${ }^{1 *}$, T. Fujiwara ${ }^{2}$, H. Tanaka ${ }^{1}$, J. Takahashi ${ }^{1}$, N. Inagaki ${ }^{1}$, \\ S. Komatsu ${ }^{3}$, A. Yamamoto ${ }^{4}$, Y. Yoshimura ${ }^{1}$ and K. Akagawa ${ }^{2}$ \\ ${ }^{1}$ Department of Obstetrics and Gynecology, Keio University School of Medicine, 35 Shinanomachi, \\ Shinjuku, Tokyo 160-8582, Japan; ${ }^{2}$ Department of Physiology, Kyorin University School of Medicine, \\ 6-20-2 Shinkawa, Mitaka, Tokyo 181-8611, Japan; ${ }^{3}$ Department of Molecular Biology, National Institute \\ of Agribiological Sciences, 2-1-2 Kannondai, Tsukuba, Ibaraki 305-8602, Japan; and ${ }^{4}$ Department of \\ Physiology, Kansai Medical College, 10-15 Humizonocho, Moriguchi, Osaka 570-8506, Japan
}

\begin{abstract}
Syntaxin is an integral membrane protein that is involved in membrane fusion. The exocytosis of the contents of cortical granules, secretory vesicles located in the cortex of an egg, modify the extracellular environment to block additional spermatozoa from penetrating the newly fertilized egg. The aim of this study was to characterize syntaxin expression in mouse oocytes, and to determine the specific isoform that is expressed. Syntaxin was demonstrated in the mouse ovary and in mouse oocytes by both western blot and reverse transcription-polymerase chain reaction analyses. Syntaxin 4 was specifically expressed in metaphase II oocytes. Syntaxin was also immunolocalized within meta-
\end{abstract}

phase II oocytes and one-cell embryos with pronuclei using laser scanning confocal microscopy. In metaphase II oocytes, syntaxin was located on the plasma membrane and in the cortex, where cortical granules are present, but was not seen at sites free of cortical granules. In one-cell embryos, no cytoplasmic region was free of syntaxin immunoreactivity. Immunoelectron microscopy detected syntaxin on both the plasma membrane and the vesicle membranes in mouse metaphase II oocytes. In conclusion the results indicate that syntaxin 4 co-localizes with cortical granules and participates in membrane fusion and exocytosis during the cortical reaction.

\section{Introduction}

Cortical granules (CGs) are membrane-bound secretory granules, derived from the Golgi apparatus, that are located immediately beneath the plasma membrane in mammalian eggs (Schuel, 1978; Gulyas, 1980; Guraya, 1982; Connors et al., 1998). CG exocytosis (cortical reaction) is one of the earliest events that take place at fertilization (Braden et al., 1954), and this exocytotic event acts to prevent polyspermy (Cran and Esper, 1990; Cherr and Ducibella, 1990; Hoodbhoy and Talbot, 1994). However, the molecular mechanism of CG exocytosis remains to be elucidated in mammalian eggs.

Vesicular trafficking and exocytosis have been investigated intensively, especially with respect to synaptic vesicles in neuronal cells. Integral membrane proteins termed SNAREs (soluble NSF attachment protein receptors) are present in the vesicle membrane ( $v$-SNAREs) and in the target membrane (t-SNAREs) (Söllner et al., 1993a). It has been proposed that SNAREs act in key steps of vesicle targeting, docking or fusion (Rothman and Warren, 1994; Scheller, 1995; Südhof, 1995; Jahn and Hanson, 1998). Identified v-SNAREs include vesicleassociated membrane proteins (VAMP) 1 and 2 as well

*Correspondence

Email: naoaki@sc.itc.keio.ac.jp as cellubrevin (Trimble et al., 1988; Baumert et al., 1989; Elferink et al., 1989; McMahon et al., 1993). The t-SNAREs include a $25 \mathrm{kDa}$ synaptosome-associated protein (SNAP-25) and its isoform (SNAP-23) as well as syntaxins, a family of t-SNAREs with multiple isoforms (Linial, 1997). Each t-SNARE binds to only a limited member of v-SNAREs (Pevsner et al., 1994), leading to a 'SNARE hypothesis' postulating a proofreading mechanism in which SNAREs contribute to the specificity of vesicle targeting, docking or fusion (Bennett et al., 1993; Rothman, 1994). VAMP, SNAP-25 and syntaxin assemble spontaneously to form ternary complexes (Wilson and Rothman, 1992; Söllner et al., 1993b), and the complexes are disassembled by $N$-ethylmaleimidesensitive fusion protein (NSF). This disassembly allows SNAREs to be recycled, and membrane fusion processes require such cyclic assembly and disassembly of complexes (Jahn and Hanson, 1998; Littleton et al., 2001).

Among the many SNARE proteins, SNAP-25 and HPC$1 /$ syntaxin $1 \mathrm{~A}$ as well as VAMP-2 play central roles in the exocytosis of synaptic vesicles (Inoue et al., 1992; Söllner et al., 1993a; Calakos and Scheller, 1996). SNAREs are also present and function in various non-neuronal tissues (adipocytes, skeletal muscles, renal cells and platelets), including the sea urchin egg and spermatozoa (Conner et al., 1997; Mandon et al., 1997; Schulz et al., 1997; Foster et al., 1998; Rea et al., 1998; Tahara et al., 1998; 
1

(a)

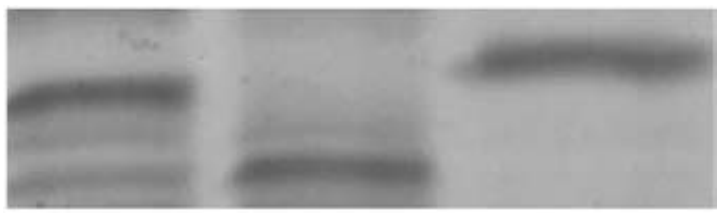

(b)

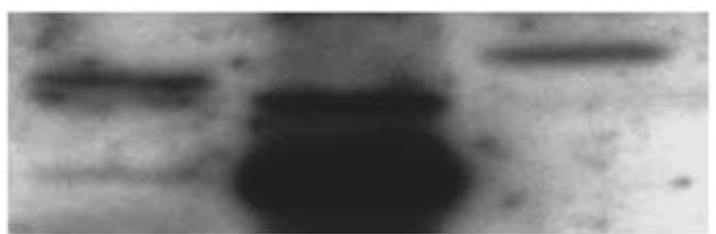

Fig. 1. Anti-syntaxin polyclonal antibody was raised in rabbits against recombinant rat syntaxin 1B (amino acids 22-180). Syntaxin recombinants (1A, 1B and 4) were solubilized in lysis buffer and SDS-PAGE was carried out. The peptides were transferred on to nitrocellulose membranes. (a) The gels were stained with Coomassie brilliant blue to detect the peptides. (b) The immunostained band in each lane represents syntaxin 1A (lane 1), 1B (lane 2) and 4 (lane 3).

Flaumenhaft et al., 1999; Yang et al., 2001). In addition, VAMP and syntaxin 1 are present in mammalian spermatozoa (Ramalho-Santos et al., 2000); SNAP-25 may be involved in CG exocytosis in mouse eggs (Ikebuchi et al., 1998).

In the present study the expression of syntaxin in mouse oocytes was investigated.

\section{Materials and Methods}

\section{Media}

Media used in these experiments included M2 medium $\left(94.7 \mathrm{mmol} \mathrm{NaCl}{ }^{-1}, 4.78 \mathrm{mmol} \mathrm{KCl} \mathrm{I}{ }^{-1}, 1.71 \mathrm{mmol}\right.$ $\mathrm{CaCl}_{2} \mathrm{I}^{-1}, 1.19 \mathrm{mmol} \mathrm{KH}_{2} \mathrm{PO}_{4} \mathrm{I}^{-1}, 1.19 \mathrm{mmol} \mathrm{MgSO}_{4}$ $I^{-1}, 4.15 \mathrm{mmol} \mathrm{NaHCO}_{3} \mathrm{I}^{-1}, 20.9 \mathrm{mmol}$ Hepes $\mathrm{I}^{-1}$, $23.3 \mathrm{mmol}$ sodium lactate $\mathrm{I}^{-1}, 0.33 \mathrm{mmol}$ sodium pyruvate $\mathrm{I}^{-1}, 5.56 \mathrm{mmol}$ glucose $\mathrm{I}^{-1}, 0.05 \mathrm{mg}$ streptomycin $\mathrm{ml}^{-1}, 100$ iu penicillin $\mathrm{G} \mathrm{ml}^{-1}, 0.001 \%(\mathrm{w} / \mathrm{v})$ phenol red and $4 \mathrm{mg} \mathrm{BSA} \mathrm{ml}^{-1}, \mathrm{pH} 7.4$ ) and $\mathrm{M} 16$ medium $\left(94.7 \mathrm{mmol} \mathrm{NaCl} \mathrm{I}{ }^{-1}, 4.78 \mathrm{mmol} \mathrm{KCl} \mathrm{I}^{-1}, 1.71 \mathrm{mmol}\right.$ $\mathrm{CaCl}_{2} \mathrm{I}^{-1}, 1.19 \mathrm{mmol} \mathrm{KH}_{2} \mathrm{PO}_{4} \mathrm{I}^{-1}, 1.19 \mathrm{mmol} \mathrm{MgSO}_{4}$ $\mathrm{I}^{-1}, 25.0 \mathrm{mmol} \mathrm{NaHCO}_{3} \mathrm{I}^{-1}, 23.3 \mathrm{mmol}$ sodium lactate $\mathrm{I}^{-1}, 0.33 \mathrm{mmol}$ sodium pyruvate $\mathrm{I}^{-1}, 5.56 \mathrm{mmol}$ glucose $\mathrm{I}^{-1}, 0.05 \mathrm{mg}$ streptomycin $\mathrm{ml}^{-1}, 100$ iu penicillin $\mathrm{G} \mathrm{ml}^{-1}, 0.001 \%$ phenol red and $4 \mathrm{mg} \mathrm{BSA} \mathrm{ml}^{-1}$, $\mathrm{pH}$ 7.4). All chemicals were purchased from Sigma Chemical Co. (St Louis, MO). All media were filtered through $0.22 \mathrm{~mm}$ filters (Millipore, Bedford, MA) and equilibrated in an atmosphere of $5 \% \mathrm{CO}_{2}$ at $37^{\circ} \mathrm{C}$.

\section{Ovary, oocyte and one-cell embryo preparation}

Ovaries were removed surgically from female ICR mice of 8-10 weeks of age from a closed colony (SLC,
Tokyo). Metaphase II (MII) oocytes were collected from superovulated ICR females at 14-15 h after administration of hCG. Cumulus-enclosed oocytes were collected in $\mathrm{M} 2$ medium. Cumulus cells were removed using $0.3 \%$ $(\mathrm{w} / \mathrm{v})$ hyaluronidase in M16 medium for $5 \mathrm{~min}$. One-cell embryos with pronuclei were flushed from the oviducts of superovulated, mated ICR females at 20-22 h after hCG administration. Oocytes and one-cell embryos were washed in M16 medium. Only mature oocytes of normal appearance with an ejected first polar body and normal, one-cell embryos with pronuclei were used in these experiments.

\section{Polyclonal antibody}

Anti-syntaxin polyclonal antibody was obtained by using recombinant rat syntaxin $1 \mathrm{~B}$ protein (His Tag fusion protein) as the antigen. The recombinant protein was produced in Escherichia coli by induction with $1 \mathrm{mmol}$ isopropyl- $\beta$-D-thiogalactopyranoside (IPTG) $\mathrm{I}^{-1}$ and was purified with an Ni-agarose column. Antiserum against rat syntaxin 1B was raised in Japanese white rabbits. An IgG fraction of this antiserum was purified on a protein A affinity column (Amersham, Arlington Heights, IL). This polyclonal antibody recognizes recombinant rat syntaxin 1A, 1B and 4 (Fig. 1). An IgG fraction of preimmune serum was purified on a Protein $A$ affinity column (Amersham) for use as a negative control.

\section{Western blot analysis}

ICR mice were killed by decapitation, and their ovaries were removed immediately. Approximately $1 \mathrm{~g}$ of ovary was homogenized in ice-cold PBS using a tissue homogenizer. Homogenates were initially centrifuged at $800 \mathrm{~g}$ for $10 \mathrm{~min}$ to pellet incompletely homogenized fragments and nuclei. Supernatants then were centrifuged at $100000 \mathrm{~g}$ for $1 \mathrm{~h}$ to obtain a crude membrane fraction. Pellets were resuspended in PBS. The protein was dissolved in sample buffer for SDSPAGE and then boiled for 5 min. Cumulus-free oocytes were homogenized with SDS-PAGE sample buffer by repeated freezing and thawing, and then by boiling for $5 \mathrm{~min}$. The protein was separated by SDS-PAGE using $12 \%(\mathrm{w} / \mathrm{v})$ acrylamide gels and transferred to polyvinylidene difluoride membranes (PVDF; Millipore). The membranes were incubated with anti-syntaxin polyclonal antibody at a 1:500 dilution, and then the membranes were washed and incubated in blocking buffer containing horseradish peroxidase (HRP)-conjugated anti-rabbit IgG. Immunoreactive bands were visualized on radiographic film (Fuji, Tokyo) using an enhanced chemiluminescence (ECL) immunoblot kit (Amersham) according to the manufacturer's instructions. 


\section{$R T-P C R$}

Total RNA was prepared from MIl oocytes and from mouse brain tissue by a modification of the method of Chomczynski and Sacchi (1987). ICR mice were decapitated, and oocytes and brain samples were collected. About 500 MII oocytes were lysed in Trizol reagent (Life Technologies, Gaithersburg, MD) containing $15 \mu \mathrm{g}$ of carrier tRNA. Brain tissue was homogenized in Trizol reagent. RNA was extracted according to the manufacturer's instructions. The RNA was suspended in a dilution buffer $\left(10 \mathrm{mmol}\right.$ Tris $\mathrm{I}^{-1}, \mathrm{pH} 7.5,0.1 \mathrm{mmol}$ EDTA $\mathrm{I}^{-1}, 2 \mathrm{mmol}$ dithiothreitol $\mathrm{I}^{-1}$, and $40 \mathrm{U}$ ribonuclease inhibitor $\mathrm{ml}^{-1}$ ).

RNA from 20 oocytes or $1 \mu \mathrm{g}$ of tissue was reversetranscribed using Moloney Murine Leukemia Virus reverse transcriptase (Pharmacia Biotech, Piscataway, NJ) for $60 \mathrm{~min}$ at $37^{\circ} \mathrm{C}$. $\mathrm{Pd}(\mathrm{N}) 6$ was used as a random primer. After completion of the reaction, first-strand cDNAs were analysed by PCR. The primer sequences and their corresponding locations in the nucleotide sequence of the syntaxin isoforms were as follows: syntaxin 1A, sense primer: 5'-TTGCCTCTGGGATCATCATGGAC-3' (530-552); antisense primer: 5'-TGCTCCССТСТGCСТCСТGT-3' (1083-1102); syntaxin 1B, sense primer: 5'-ACTCGCAGATGACAAAGCAAGCC-3' (548-570); antisense primer: 5'-CTGGGTCTGTTTTGGGAGTGAGC-3' (953-975); syntaxin 4, sense primer: 5'CGACAGGACCCATGAGTTGAGGC-3' (6-28); antisense primer: 5'-GGTGATGCCAATGATGACAGCCAA-3' (859882). These sequence data are available under GenBank accession numbers M95735, M95734 and L20821, respectively. The expected size of the syntaxin 4 PCR products was $816 \mathrm{bp}$. PCR was initiated by adding $50 \mu \mathrm{l}$ of a mixture containing PCR buffer, Taq polymerase (Perkin-Elmer, Norwalk, CT), and corresponding sense and antisense primers. PCR analysis was conducted in a Perkin-Elmer Cetus DNA thermal cycler. One cycle of PCR consisted of denaturation at $95^{\circ} \mathrm{C}$ for $60 \mathrm{~s}$, primer annealing at $58^{\circ} \mathrm{C}$ for $120 \mathrm{~s}$, and primer extension at $72^{\circ} \mathrm{C}$ for $60 \mathrm{~s}$. Amplification consisted of 40 cycles. PCR products were subjected to electrophoresis on $1.5 \%(\mathrm{w} / \mathrm{v})$ agarose gels and stained with ethidium bromide.

\section{Immunofluorescence}

MII oocytes and one-cell embryos with pronuclei were washed, fixed with $4 \%(\mathrm{w} / \mathrm{v})$ paraformaldehyde for $30 \mathrm{~min}$ at $37^{\circ} \mathrm{C}$, blocked in $5 \%$ goat serum, and permeabilized with $0.2 \%(\mathrm{v} / \mathrm{v})$ Triton X-100 in 5\% goat serum for $15 \mathrm{~min}$. The zona pellucida was removed from oocytes and one-cell embryos with Tyrode's solution. Rabbit polyclonal anti-syntaxin antibody was applied as a primary antibody (dilution; $1: 500$ ) for $24 \mathrm{~h}$ at $4^{\circ} \mathrm{C}$. A negative control experiment was run with replacement of the primary antibody with preimmune rabbit IgG at the same concentration. After repeated washing in 5\% goat serum, goat anti-rabbit IgG conjugated with rhodamine was applied at a 1:600 dilution as a secondary antibody for $1 \mathrm{~h}$ at $37^{\circ} \mathrm{C}$. To label the CGs additionally, the oocytes or one-cell embryos subsequently were washed and incubated for $10 \mathrm{~min}$ at $37^{\circ} \mathrm{C}$ in $10 \mu \mathrm{g}$ of fluorescent lectin $\mathrm{ml}^{-1}$ (fluorescein isothiocyanate (FITC) conjugated to Lens culinaris agglutinin (LCA; Sigma), to label the CG with LCA. Unbound lectin was removed by washing, and fluorescence from rhodamine and FITC was visualized by excitation at $488 \mathrm{~nm}$, using an argon laser with a $570 \mathrm{~nm}$ filter and a BP $535 \mathrm{~nm}$ filter respectively, in a confocal microscope (LSM-GB200, Olympus, Tokyo).

\section{Immunoelectron microscopy}

The pre-embedding silver enhancement immunogold method was used for immunoelectron microscopy (Nakamura et al., 2000) with slight modifications. Briefly, MII oocytes were fixed for $2 \mathrm{~h}$ using $4 \%$ paraformaldehyde in PBS (pH 7.4). The oocytes were frozen and thawed using 14\% (v/v) glycerol and 35\% $(\mathrm{w} / \mathrm{v})$ sucrose in liquid $\mathrm{N}_{2}$, and were reacted with the anti-syntaxin polyclonal antibody (dilution; 1:500), and then incubated with secondary antibodies conjugated to colloidal gold (diameter $1.4 \mathrm{~nm}$ ). The gold labelling was intensified using a silver enhancement kit, HQ silver (Nanoprobes, Yaphank, NY). The control experiment was performed with replacement of the primary antibody with preimmune rabbit IgG. Ten oocytes were examined in each condition and the experiment was repeated twice.

\section{Results}

Expression of syntaxin-like protein in ovaries and oocytes

Polyclonal antibodies were used to detect syntaxinlike protein in extracts from mouse ovaries and brain. The anti-syntaxin antibody recognized a single distinct 35 kDa band in crude membrane fractions (Fig. 2a) from brain (lane 1) and ovary (lanes 2 and 3), confirming that a syntaxin-like protein is present in the ovary.

Syntaxin-like protein was detected in MII oocytes by analysing extracts from oocytes by western blot analysis as above. An immunoreactive band was again detected in the total lysate from 500 MII oocytes (lane 2), similar to those seen for the brain and ovary (Fig. 2b). No other significant band was seen in the lane. This $35 \mathrm{kDa}$ band in brain, ovary and MII oocytes was consistent with the expected size of syntaxin.

\section{Expression of syntaxin mRNAs in metaphase II oocytes}

As the anti-syntaxin antibody could detect several isoforms of recombinant syntaxin, RT-PCR was carried out using total RNA from MII oocytes and from brain 


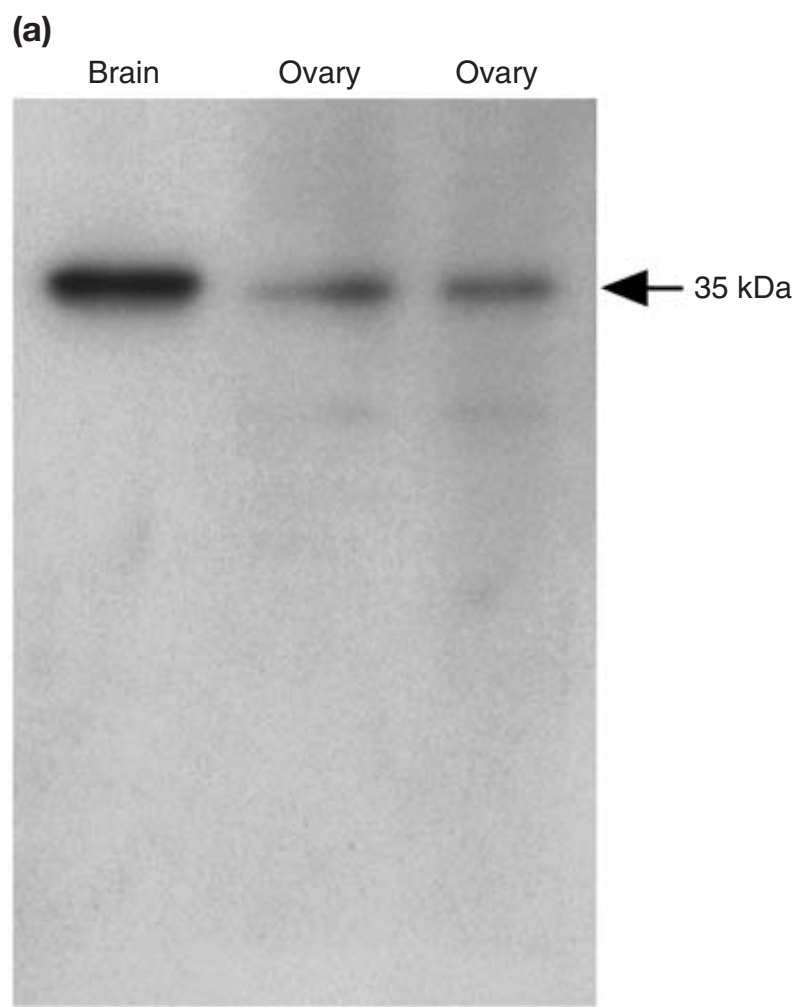

(b)

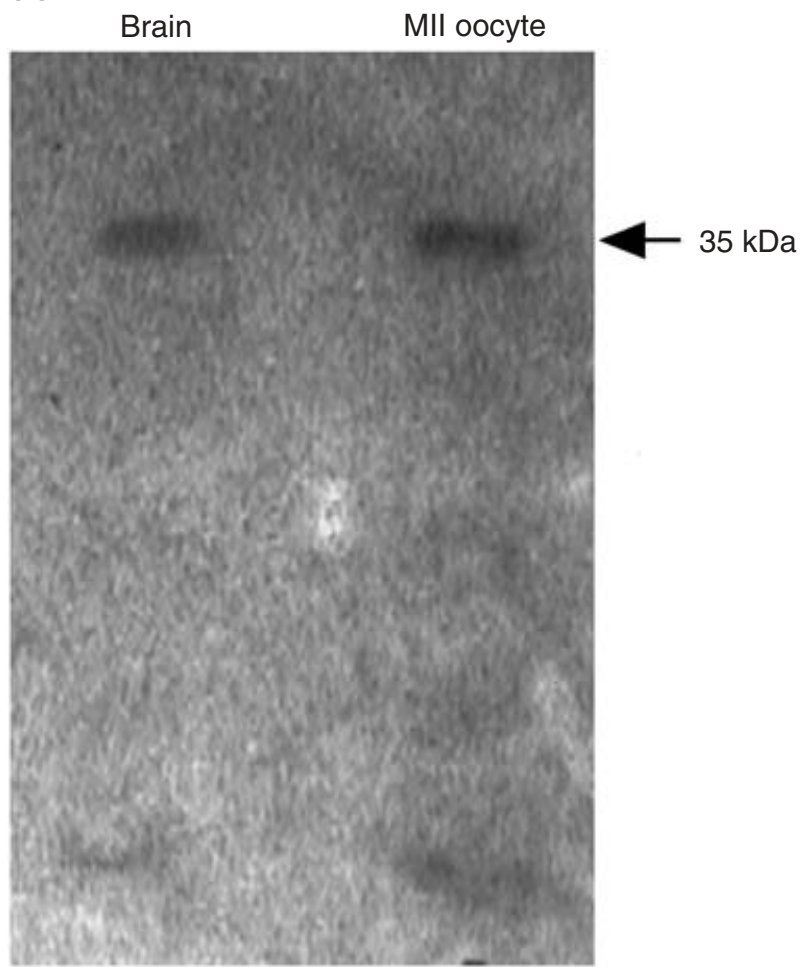

Fig. 2. Western blot analysis of syntaxin. Proteins were extracted and separated by gel electrophoresis. The gel was blotted on to a membrane, and deposited proteins were probed with anti-syntaxin antibody. (a) Proteins from the brain $(0.25 \mu \mathrm{g}$ in lane 1$)$ served as a positive control, two different aliquots of proteins from the ovary were also loaded on to the gel ( $25 \mu \mathrm{g}$ in lane $2 ; 50 \mu \mathrm{g}$ in lane 3$)$.

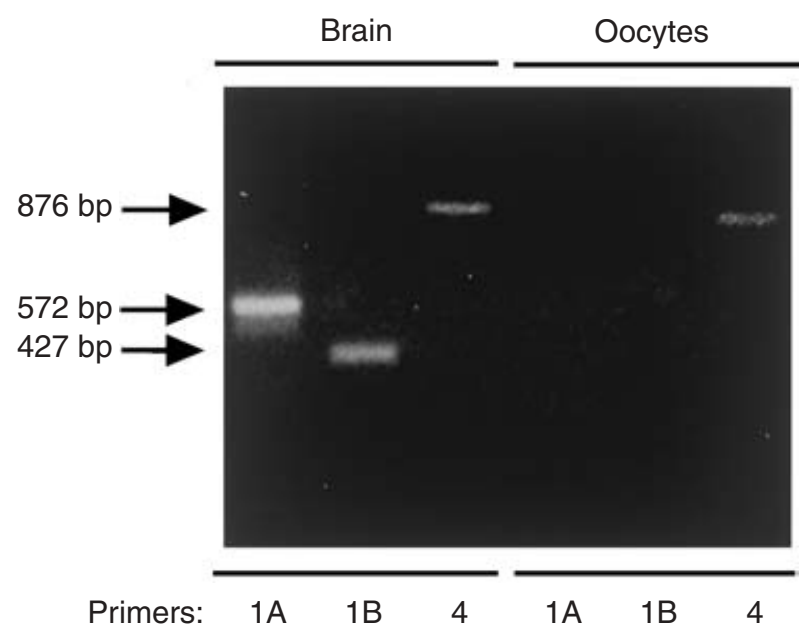

Fig. 3. Syntaxin mRNA expression in metaphase II (MII) oocytes. About 500 MII oocytes were lysed in Trizol reagent with $15 \mu \mathrm{g}$ of carrier tRNA, and RNA was extracted. The RNAs were resuspended in RNA dilution buffer and an aliquot was subjected to RT-PCR. An ethidium bromide-stained agarose gel of the oocyte RT-PCR products using primers specific for syntaxin isoforms is shown. As a positive control, RNA isolated from the brain was subjected to RTPCR using the same primers. RNA from 20 oocytes or $1 \mu \mathrm{g}$ of brain tissue was reverse-transcribed using Moloney murine leukaemia virus reverse transcriptase for $60 \mathrm{~min}$ at $37^{\circ} \mathrm{C} . \operatorname{Pd}(\mathrm{N}) 6$ was used as a random primer. The first-strand cDNAs were amplified by PCR. Each PCR cycle consisted of denaturation at $95^{\circ} \mathrm{C}$ for $60 \mathrm{~s}$, primer annealing at $58^{\circ} \mathrm{C}$ for $120 \mathrm{~s}$, and primer extension at $72^{\circ} \mathrm{C}$ for $60 \mathrm{~s}$ for a total of 40 cycles. Only the amplification product of the size predicted for syntaxin 4 was observed in extracts from MII oocytes.

to identify the specific isoform expressed (Fig. 3). Each primer set used in these experiments was specific for one of three syntaxin isoforms (rat syntaxin 1A, 1B and 4) (Bennett et al., 1992, 1993; Mandon et al., 1996). RT-PCR analysis revealed that only syntaxin 4 was expressed in MII oocytes, and only the predictedsize amplification product for syntaxin 4 was observed. Neither syntaxin 1A nor 1B was detectable in the MII oocytes. The syntaxin 4 RT-PCR product was cloned and sequenced, and was found to be identical to the reported sequence for mouse syntaxin 4 (Genbank accession no. U76832). Furthermore, RT-PCR carried out with primers for syntaxin 1A, 1B, 2, 3, 4 and 5 indicated that only the product for syntaxin 4 was detectable (data not shown).

The immunostained $35 \mathrm{kDa}$ band in membrane fractions of both the brain and ovary had the expected molecular mass of syntaxin. (b) Proteins from the brain $(0.5 \mu \mathrm{g}$ in lane 1$)$ served as a positive control and proteins from oocytes were also loaded (extract from 500 oocytes in lane 2). Again, the immunostained $35 \mathrm{kDa}$ band in both the brain membrane fraction and oocyte preparation had the expected molecular mass of syntaxin. 

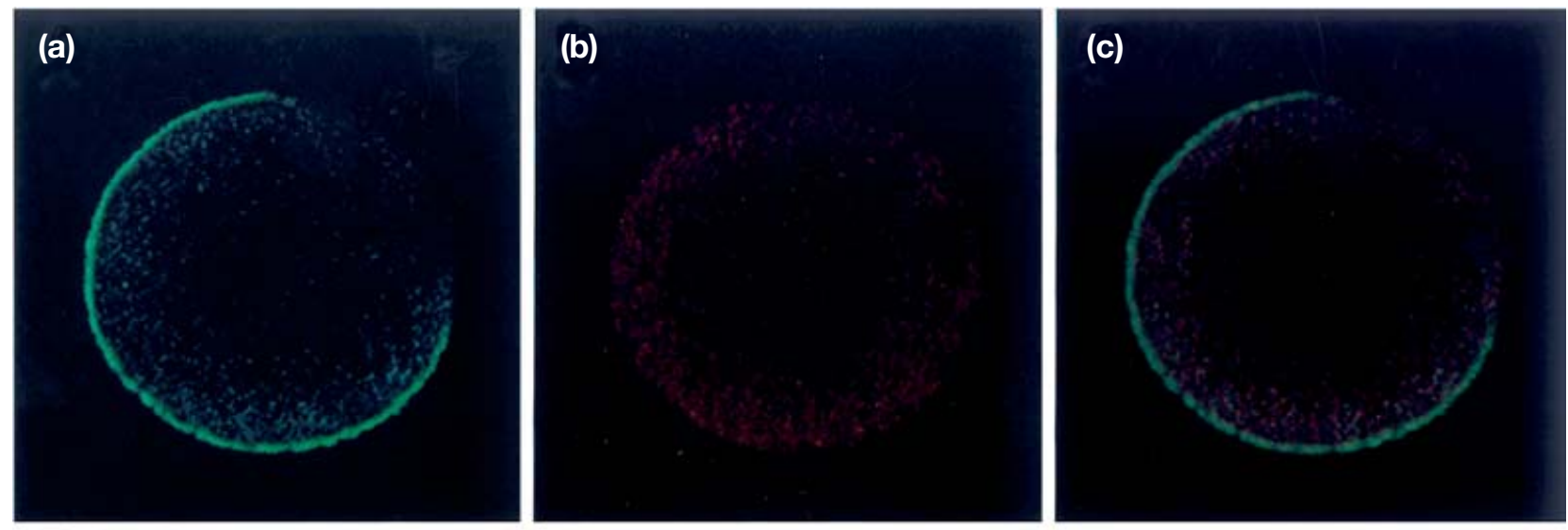

(d)

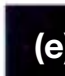

(e)
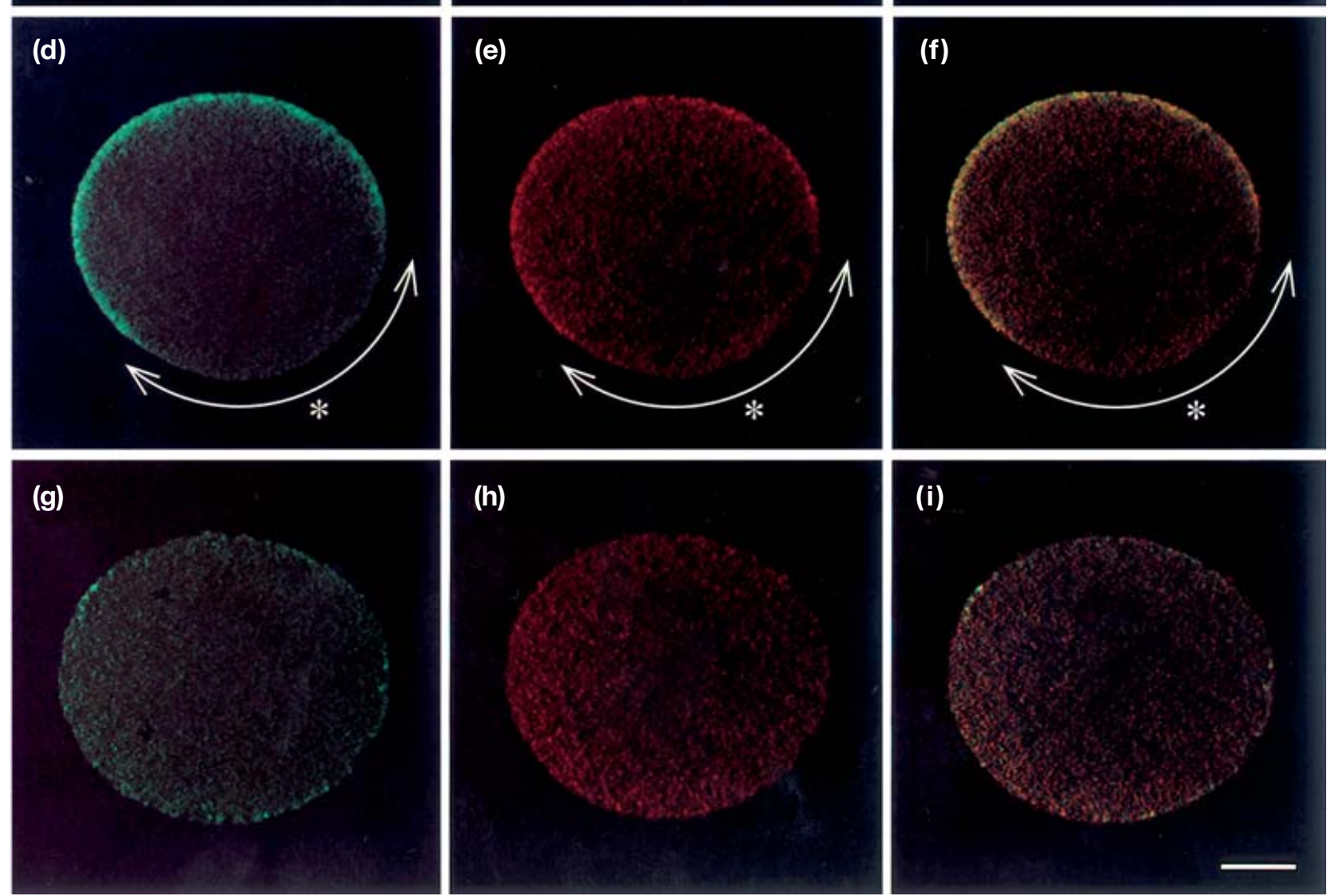

Fig. 4. (a,d,g) Immunofluorescence labelling of syntaxin and cortical granules (CGs). After fixation and permeabilization, CGs were stained with fluorescein isothiocyanate (FITC)-conjugated Lens culnaris agglutinin. (e,h) Syntaxin immunoreactivity was detected using an anti-syntaxin primary antibody and a rhodamine-conjugated secondary antibody. $(\mathrm{f}, \mathrm{i})$ The double-labelled oocytes and onecell embryos show both syntaxin (red) and CG (green) immunoreactivity. (b,c) A negative control experiment was run in which the primary antibody was replaced with preimmune rabbit IgG. Confocal microscopy with filters specific for FITC, rhodamine and both were used to localize CG and syntaxin in metaphase II (MII) oocytes ( $a-f$ ) and one-cell embryos (g-i). Syntaxin immunoreactivity (red) was seen predominantly on the plasma membrane and cortical region in MII oocytes (e). This staining co-localized with CG staining, also showing the absence of syntaxin immunofluorescence in the CG-free area (arrows with asterisks in $\mathrm{d}-\mathrm{f}$ ). After fertilization, syntaxin immunoreactivity too was detected on the plasma membrane and in the cortical region of one-cell embryos (g-i). The staining-free region of syntaxin observed in the MII oocytes was not detected (e,h). Ten oocytes were examined in each condition. The experiment was performed three times. A representative result of one experiment is shown. Scale bar represents $20 \mu \mathrm{m}$. 

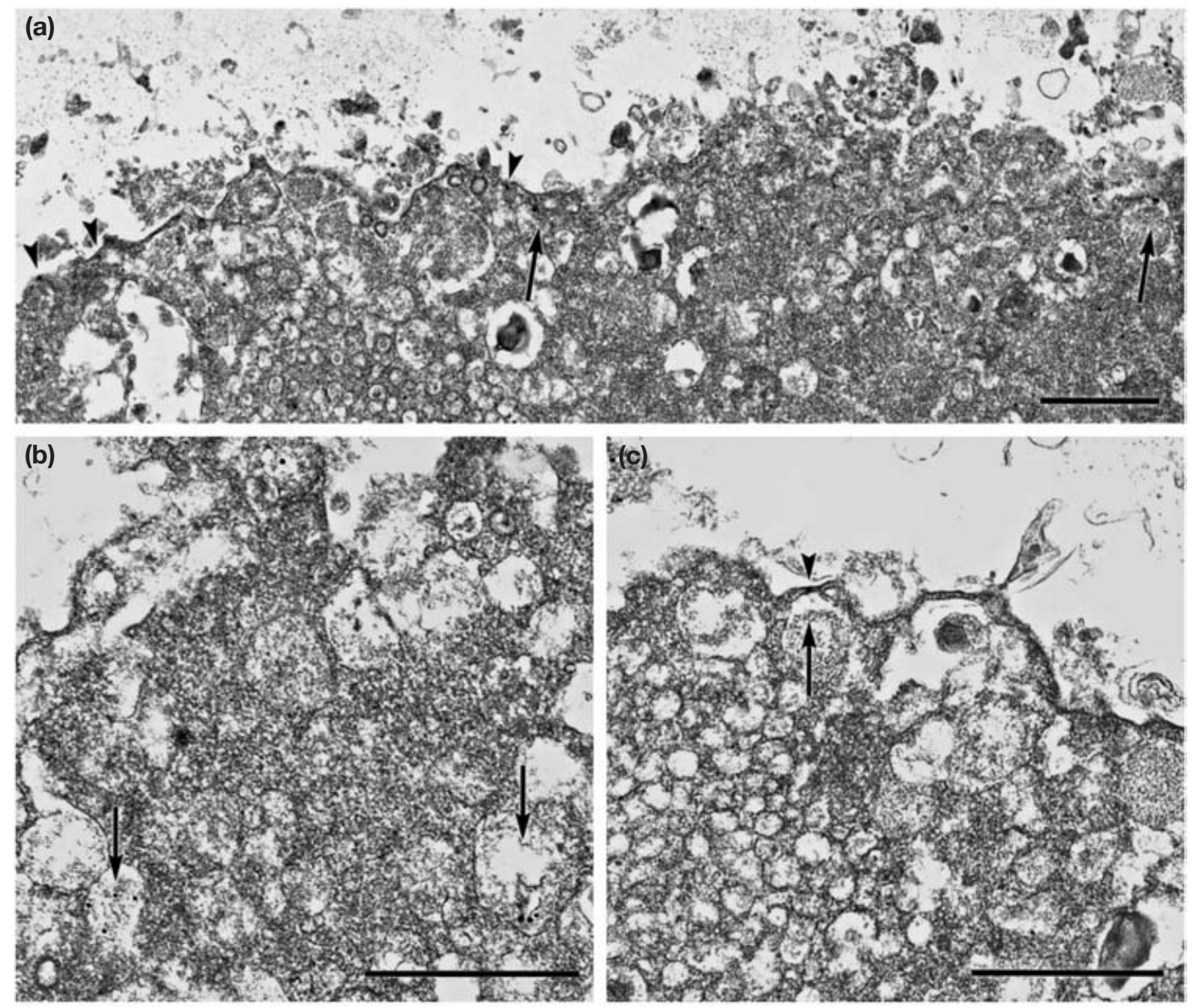

Fig. 5. Immunogold electron micrographs of mouse metaphase II (MII) oocytes using antibodies to syntaxin. MII oocytes were fixed and processed for pre-embedding immunoelectron microscopy. (a) Silver enhanced gold particles were detected on the membranes of CGs in the cortical region of MII oocytes (arrows) and on the plasma membrane (arrowheads). (b,c) As represented at higher magnification, gold particles can be seen on the membranes of CGs (arrows) and on the plasma membrane (arrowhead). Scale bars represent $1 \mu \mathrm{m}$.

Thus the immunoreactive band in oocytes was thought to represent syntaxin 4 .

\section{Localization of syntaxin on metaphase II oocytes and one-cell embryos with pronuclei}

Syntaxin 4 was localized within MII oocytes and one-cell embryos by laser scanning confocal fluorescence microscopy. For a clear characterization of the intracellular location of syntaxin 4 with respect to CGs, the same MII oocyte and one-cell embryo was stained with two different fluorescent dyes. CGs were stained with FITC-LCA, and syntaxin immunostaining was detected with a rhodamine-conjugated secondary antibody. Preimmune rabbit $\lg G$ was used as a negative control (Fig. 4a-c). Immunofluorescence was also not detected in non-permeabilized MII oocytes (data not shown). In MII oocytes syntaxin immunoreactivity resided predominantly on the plasma membrane and the cortex region. The syntaxin staining pattern in the cortex also indicated a region free of immunostaining that coincided with the cortical free area (arrows in Fig. 4d-f). Thus the distribution of syntaxin immunoreactivity was the same as that of the CGs detected with FITC-LCA staining. Although syntaxin immunoreactivity was also detected on the plasma membrane and in the cytoplasm in one-cell embryos, there was no prominent staining in the cortical region similar to that seen in MII oocytes (Fig. 4g-i). 
Immunoelectron microscopy of syntaxin in the metaphase II oocytes

The detailed intracellular localization of syntaxin in MII oocytes was analysed using immunoelectron microscopy. Silver-enhanced gold particles were detected on the membranes of CGs (arrows in Fig. $5 a$ and b). A few gold particles were also present on the plasma membrane (arrow heads in Fig. 5a and 5c), but no gold particles were detected in other organelles. Controls consisting of oocytes incubated with preimmune rabbit IgG instead of the primary antibody showed almost no gold particles.

\section{Discussion}

Some of the SNARE proteins, which form ternary complexes and mediate membrane fusion in several exocytotic cell types, have been identified in mammalian (Ikebuchi et al., 1998) and non-mammalian (Conner et al., 1997; Tahara et al., 1998) oocytes. In mouse oocytes, SNAP-25 has been shown to be involved in $\mathrm{Ca}^{2+}$-dependent CG exocytosis, and sperm-induced CG exocytosis is inhibited in botulinum neurotoxin A-treated eggs (Ikebuchi et al., 1998). These studies have led to a hypothesis that the mechanism of CG exocytosis in eggs is similar to that of synaptic vesicles in neurones as well as to that in other non-neuronal tissues. Western blot analysis revealed syntaxin-like protein expression in mature murine ovary and oocytes. The findings provide strong support for the proposal of a common mechanism, as syntaxin is thought to be an essential component of the fusion machinery.

The syntaxin isoforms $1 \mathrm{~A}, 1 \mathrm{~B}$ and 4 have been shown previously to be at least partially located in the plasma membrane of neurones and some non-neuronal cells, and to function in the exocytotic pathway by forming ternary complexes with VAMP and SNAP-25 (Inoue et al., 1992; Söllner et al., 1993a; Calakos and Scheller, 1996; Mandon et al., 1996; Foster et al., 1998; Rea et al., 1998; Flaumenhaft et al., 1999). Whereas syntaxin 1A and $1 \mathrm{~B}$ are involved in the docking or fusion reaction between neurotransmitter-containing vesicles and the plasma membrane in neuronal cells, syntaxin 4 has been found in a variety of tissues including brain, lung, spleen, kidney and fat (Bennett et al., 1993). Syntaxin 4 has been shown to be involved in the regulation of vesicle trafficking, docking, or fusion events in non-neuronal cells as a complex with VAMP-2 and SNAP-23 or -25 . The RT-PCR results in the present study using primers for syntaxin 1A, 1B, 2, 3, 4 and 5 indicated that only the product for syntaxin 4 was detectable (data not shown). This is consistent with the conclusion that the single immunoreactive band in oocytes is syntaxin 4 . Since functional SNAP-25 is present in mouse oocytes (Ikebuchi et al., 1998), syntaxin 4 in mouse oocytes may form ternary complexes with VAMP-2 and SNAP-25 to mediate the CG exocytosis as in other non-neuronal cells.

We have subsequently localized syntaxin 4 within mouse oocytes by using laser scanning confocal microscopy and immunoelectron microscopy. These immunohistochemical findings provide strong evidence that syntaxin 4 is expressed on the CG membrane as well as on the plasma membrane. In sea urchin oocytes Conner et al. (1997) detected a syntaxin-like molecule not only in the plasma membrane fraction but also in the CG fraction. Although syntaxin was originally described as an integral plasma membrane protein, evidence arose indicating that it was present too on the neuronal synaptic vesicle membrane (Nichols et al., 1997; Ungermann et al., 1998). Highly purified synaptic vesicles have been shown to contain syntaxin and SNAP25, members of the t-SNARE family, as well as VAMP, a neuronal v-SNARE (Walch-Solimena et al., 1995). The immunohistochemical localization of syntaxin 4 shown in the present study coincided well with the location of CGs in mouse MII oocytes, and the results of immunoelectron microscopy showed that syntaxin is present mainly on the vesicle membrane in mouse oocytes.

Oocyte maturation is accompanied by formation of a CG-free domain (CGFD) overlying the metaphase II spindle (Ducibella et al., 1988a). It was also observed that this CGFD is found in MII mouse oocytes (this study). No FITC-LCA fluorescence was detected immediately adjacent to the first polar body, where the meiotic spindle was present. The absence of syntaxin immunoreactivity in the CGFD also indicates that this molecule is located on the CG membrane.

In MIl oocytes, immunoreactivity for syntaxin 4 was observed mainly on the plasma membrane and in the cortex, with a small portion located deep in the cytoplasm. These results can be explained in one of two ways. The first possibility is that these molecules may be undergoing transfer from their site of origin, the Golgi apparatus, to their ultimate destination, the plasma membrane (Kasai and Akagawa, 2001). The second possibility is that deep cytoplasmic immunoreactivity represents CG located deep in the cytoplasm. In general CGs are membrane-bound vesicles that originate from the Golgi apparatus and migrate toward the cortex during oocyte maturation. Although most CGs are located peripherally by the end of oocyte maturation, as in GV stage oocytes and MII stage oocytes, some CGs still reside in the interior of the mature oocyte (Ducibella et al., 1988b; Abbott et al., 2001). These reports support our suggestion of a small portion of immunoreactivity in the deep cytoplasm.

After fertilization, faint fluorescence of syntaxin was observed on the plasma membrane but a syntaxin immunoreactivity-free area, corresponding to the CG distribution seen in MIl oocytes, was not seen. FITCLCA fluorescence of residual CG products was observed 
on the plasma membrane in one-cell embryos. During exocytotic membrane fusion, the SNARE proteins of the membrane (t-SNARE) interact with those of the vesicle ( $v$-SNARE) to form ternary complexes, and are thought to change the molecular configuration of SNARE proteins. The formation of ternary complexes could alter access by an antibody, or the configurational change of the syntaxin molecule could affect antibody affinity for syntaxin on the plasma membrane. This speculation might explain the decrease of syntaxin immunoreactivity on the oocyte plasma membrane after fertilization.

Although our results show the expression of syntaxin 4 in mouse oocytes, the exact functional roles remain to be elucidated. Investigation of the effects of micro-injection experiments using syntaxin antagonists (botulinum neurotoxin or anti-syntaxin antibody) would provide further understanding of the functional roles of this molecule during cortical reaction.

In conclusion, the present study demonstrates that syntaxin 4 mRNA is detected in MIl oocytes and that syntaxin 4 expression may be distributed in a different manner in MII oocytes from that in one-cell embryos. These results indicate that syntaxin 4 co-localizes with CGs in the cortex, where it is likely to function in membrane fusion during CG exocytosis.

The authors thank all the members of the Department of Physiology at Kyorin University School of Medicine for their support and technical assistance, and S. Suzuki for helpful discussions. This work was supported in part by a Grant-In-Aid for scientific research from the Ministry of Education, Science and Culture of Japan (No. 11671649).

\section{References}

Abbott AL, Fissore RA and Ducibella T (2001) Identification of a translocation deficiency in cortical granule secretion in preovulatory mouse oocytes Biology of Reproduction 65 1640-1647

Baumert M, Maycox PR, Navone F, De Camilli P and Jahn R (1989) Synaptobrevin: an integral membrane protein of 18,000 daltons present in small synaptic vesicles of rat brain EMBO Journal 8 379-384

Bennett MK, Calakos N and Scheller RH (1992) Syntaxin: a synaptic protein implicated in the docking of synaptic vesicles at presynaptic active zones Science 257 255-259

Bennett MK, Garcia Arraras JE, Elferink LA, Peterson K, Fleming AM, Hazuka CD and Scheller RH (1993) The syntaxin family of vesicular transport receptors Cell 74 863-873

Braden AWH, Austin CR and David HA (1954) The reaction of the zona pellucida to sperm penetration Journal of Experimental Zoology $\mathbf{1 8 0}$ 251-266

Calakos N and Scheller RH (1996) Synaptic vesicle biogenesis, docking, and fusion: a molecular description Physiological Reviews 76 1-29

Cherr GN and Ducibella T (1990) Activation of the mammalian egg: cortical granule distribution, exocytosis, and the block to polyspermy. In Fertilization in Mammals pp 309-334 Eds BD Bavister, J Cummins and ERS Roldan. Serono Symposia, Norwell MA

Chomczynski P and Sacchi N (1987) Single-step method of RNA isolation by acid guanidinium thiocyanate-phenol-chloroform extraction Analytical Biochemistry 162 156-159

Conner S, Leaf D and Wessel GM (1997) Members of the SNARE hypothesis are associated with cortical granule exocytosis in the sea urchin egg Molecular Reproduction and Development 48 106-118
Connors SA, Kanatsu Shinohara M, Schultz RM and Kopf GS (1998) Involvement of the cytoskeleton in the movement of cortical granules during oocyte maturation, and cortical granule anchoring in mouse eggs Developmental Biology 200 103-115

Cran DG and Esper CR (1990) Cortical granules and the cortical reaction in mammals Journal of Reproduction and Fertility Supplement 42 177-188

Ducibella T, Anderson E, Albertini DF, Aalberg J and Rangarajan S (1988a) Quantitative studies of changes in cortical granule number and distribution in the mouse oocyte during meiotic maturation Developmental Biology 130 184-197

Ducibella T, Rangarajan S and Anderson E (1988b) The development of mouse oocyte cortical reaction competence is accompanied by major changes in cortical vesicles and not cortical granule depth Developmental Biology 130 789-792

Elferink LA, Trimble WS and Scheller RH (1989) Two vesicle-associated membrane protein genes are differentially expressed in the rat central nervous system Journal of Biological Chemistry 26411 061-11 064

Flaumenhaft R, Croce K, Chen E, Furie B and Furie BC (1999) Proteins of the exocytotic core complex mediate platel et al pha-granule secretion Journal of Biological Chemistry 274 2492-2501

Foster LJ, Yeung B, Mohtashami M, Ross K, Trimble WS and Klip A (1998) Binary interactions of the SNARE proteins syntaxin-4, SNAP23, and VAMP-2 and their regulation by phosphorylation Biochemistry 37 $11089-11096$

Gulyas BJ (1980) Cortical granules of mammalian eggs International Review of Cytology 63 357-392

Guraya SS (1982) Recent progress in the structure, origin, composition, and function of cortical granules in animal egg International Review of Cytology 78 257-260

Hoodbhoy T and Talbot P (1994) Mammalian cortical granules: contents, fate, and function Molecular Reproduction and Development 39 439448

Ikebuchi Y, Masumoto N, Matsuoka T, Yokoi T, Tahara M, Tasaka K, Miyake A and Murata Y (1998) SNAP-25 is essential for cortical granule exocytosis in mouse eggs American Journal of Physiology C 274 14961500

Inoue A, Obata K and Akagawa K (1992) Cloning and sequence analysis of cDNA for a neuronal cell membrane antigen, HPC-1 Journal of Biological Chemistry 267 $10613-10619$

Jahn R and Hanson PI (1998) SNAREs line up in new environment Nature 393 14-15

Kasai K and Akagawa K (2001) Roles of the cytoplasmic and transmembrane domains of syntaxins in intracellular localization and trafficking Journal of Cell Science 114 3115-3124

Linial M (1997) SNARE proteins - why so many, why so few? Journal of Neurochemistry 69 1781-1792

Littleton JT, Barnard RJO, Titus SA, Slind J, Chapman ER and Ganetzky B (2001) SNARE-complex disassembly by NSF follows synapticvesicle fusion Proceedings National Academy of Sciences USA 98 12 233-12 238

McMahon HT, Ushkaryov YA, Edelmann L, Link E, Binz T, Niemann H, Jahn R and Südhof TC (1993) Cellubrevin is a ubiquitous tetanus-toxin substrate homologous to a putative synaptic vesicle fusion protein Nature 364 346-349

Mandon B, Chou CL, Nielsen S and Knepper MA (1996) Syntaxin-4 is localized to the apical plasma membrane of rat renal collecting duct cells: possible role in aquaporin-2 trafficking Journal of Clinical Investigation 98 906-913

Mandon B, Nielsen S, Kishore BK and Knepper MA (1997) Expression of syntaxins in rat kidney American Journal of Physiology F 273 718-730

Nakamura N, Yamamoto A, Wada Y and Futai M (2000) Syntaxin 7 mediates endocytic trafficking to late endosomes Journal of Biological Chemistry 275 6523-6529

Nichols BJ, Ungerman C, Pelham HRB, Wickner WT and Haas A (1997) Homotypic vacuolar fusion mediated by $\mathrm{t}-$ and $\mathrm{v}$-SNAREs Proceedings National Academy of Sciences USA 387 199-202

Pevsner J, Hsu SC, Braun JE, Calakos N, Ting AE, Bennett MK and Scheller RH (1994) Specificity and regulation of a synaptic vesicle docking complex Neuron 13 353-361 
Ramalho-Santos J, Moreno RD, Sutovsky P, Chan AW, Hewitson L, Wessel GM, Simerly CR and Schatten G (2000) SNAREs in mammalian sperm: possible implications for fertilization Developmental Biology 223 54-69

Rea S, Martin LB, McIntosh S, Macaulay SL, Ramsdale T, Baldini G and James DE (1998) Syndet, an adipocyte target SNARE involved in the insulin-induced translocation of GLUT4 to the cell surface Journal of Biological Chemistry 27318 784-18 792

Rothman JE (1994) Mechanisms of intracellular protein transport Nature 372 55-63

Rothman JE and Warren G (1994) Implications of the SNARE hypothesis for intracellular membrane topology and dynamics Current Biology 4 220-233

Scheller RH (1995) Membrane trafficking in the presynaptic nerve terminal Neuron 14 893-897

Schuel H (1978) Secretory functions of egg cortical granules in fertilization and development Gamete Research 1 299-302

Schulz JR, Wessel GM and Vacquier VD (1997) The exocytosis regulatory proteins syntaxin and VAMP are shed from sea urchin sperm during the acrosome reaction Developmental Biology 191 80-87

Söllner T, Whiteheart SW, Brunner $M$, Erdjument Bromage $H$, Geromanos S, Tempst P and Rothman JE (1993a) SNAP receptors implicated in vesicle targeting and fusion [see comments] Nature 362 318-324

Söllner T, Bennett MK, Whiteheart SW, Scheller RH and Rothman JE (1993b) A protein assembly-disassembly pathway in vitro that may correspond to sequential steps of synaptic vesicle docking, activation, and fusion Cell 75 409-418

Südhof T (1995) The synaptic vesicle cycle: a cascade of protein-protein interactions Nature 375 645-653
Tahara M, Coorssen JR, Timmers K, Blank PS, Whalley T, Scheller R and Zimmerberg J (1998) Calcium can disrupt the SNARE protein complex on sea urchin egg secretory vesicles without irreversibly blocking fusion Journal of Biological Chemistry 27333 667-33 673

Trimble WS, Cowan DM and Scheller RH (1988) VAMP-1: a synaptic vesicle-associated integral membrane protein Proceedings National Academy of Sciences USA 85 4538-4542

Ungermann C, Nichols BJ, Pelham HRB and Wickner W (1998) A vacuolar v-t-SNARE complex, the predominant form in vivo and on isolated vacuoles, is disassembled and activated for docking and fusion Journal of Cell Biology 140 61-69

Walch-Solimena C, Blasi J, Edelmann L, Chapman ER, von Mollard GF and Jahn $\mathbf{R}$ (1995) The t-SNAREs syntaxin 1 and SNAP-25 are present on organelles that participate in synaptic vesicle recycling Journal of Cell Biology 128 637-645

Wilson DW and Rothman JE (1992) Expression and purification of recombinant $\mathrm{N}$-ethylmaleimide-sensitive fusion protein from Escherichia coli. Methods in Enzymology 219 309-318

Yang C, Coker KJ, Kim JK, Mora S, Thurmond DC, Davis AC, Yang B, Williamson RA, Shulman GI and Pessin JE (2001) Syntaxin 4 heterozygous knockout mice develop muscle insulin resistance Journal of Clinical Investigation 107 1311-1318

Received 27 January 2003.

First decision 20 February 2003.

Revised manuscript received 20 March 2003.

Accepted 2 April 2003. 